\title{
TRATAMENTO JURÍDICO DA RETROCESSÃO
}

\author{
MANOEL EUGÊNIO MARQUES MUNHOZ
}

(Auxiliar de Ensino de Direito Administrativo.)

1. Influência do Direito Civil - 2. Conceito de Retrocessão - 3. Natureza Jurídica - 4. Retrocessão e Propriedade Resolúvel - 5. Teoria do Ato Administrativo - Motivos Determinantes.

1. É notória a influência do Direito Civil sôbre o Administrativo, atribuída à precedência histórica da elaboração do primeiro em relação ao segundo. SEABRA FAGUNDES acentua o que essa influência representou para a formação do Direito Administrativo: "A preeminência das instituições de Direito Privado na cronologia da evolução do Direito, resultante da estrutura absolutista do Estado, que levava o poder público à fuga da disciplina jurídica, enquanto caminhava para a regulação legal das relações entre os indivíduos como pessoas privadas, fêz que o Direito Administrativo, o direito através do qual se dinamizam, por excelência, as relações do binômio Estado - indivíduo, tivesse na legislação civil a origem de algumas de suas principais instituições, dela recebendo-as por cissiparidade". (')

Como fenômeno de antecipação, a influência do Direito Civil não se limitou à estratificação de princípios mais tarde utilizados pelo Direito Administrativo e à inclusão, em seu corpo específico de leis, de normas nìtidamente de Direito Público. A primazia dos estudos civilistas gerou também uma mentalidade jurídica moldada sob as diretrizes do Direito Privado. Princípios de Direito Público, contidos ou não no Código Civil, são estruturados e pesquisados de conformidade com o civilismo que se fêz preponderante.

2. Foi o que ocorreu com a retrocessão, ou seja, segundo $H$.

( 1) Da Contribuição do Código Civil para o Direito Administrativo, in Rev. Dir. Adm., vol 78, pág. 1. 
LOPES MEIRELLES, "o direito do ex-proprietário de reaver os bens não utilizados no fim para o qual tenham sido desapropriados".

Embora prevista expressamente na lei de desapropriação anterior $\left({ }^{3}\right)$, deixou de sê-lo na atual, a pretexto de constituir matéria reservada à disciplina do Direito Privado, anotando FRANCISCO CAMPOS que o instituto estava erradamente assimilado ao da desapropriação.

Hoje se restabelece o entendimento de que a retrocessão se configura como instituto eminentemente de Direito Público, assim como - da desapropriação, cuja fonte é de ordem constitucional e com o qual se entrelaça de modo indissociável.

Todavia, continua no artigo 1.150 do Código Civil norma a respeito do direito do expropriado: "A União, o Estado, ou o Município, oferecerá ao ex-proprietário o imóvel desapropriado, pelo preço que o foi, caso não tenha o destino para que se desapropriou".

CLÓVIS BEVILAQUA viu aí um direito pessoal, corolário aliás da inclusão do preceito entre os dispositivos que regem a preempção ou preferência, cuja inobservância se resolve em perdas e danos. "O ex-proprietário, por isso que perdeu o seu domínio, não tem o direito de reivindicação, que, errôneamente, se the reconhecia outrora; mas, sim, o direito de preempção, aliás sob a forma particular de não depender da alienação da coisa e, sim, tão sòmente de não the ser dado o destino para que se desapropriou. - Se a União, o Estado ou o Município, não cumprir a sua obrigação de oferecer o bem ao ex-proprietário, no caso previsto pelo art. 1.150, incorrerá em perdas e danos (art. 1.156)".

Tratava-se de reação à opinião de CARLOS DE CARVALHO, de que resultara, aliás, o artigo 855 da Nova Consolidação de 1899, onde se estabeleceu que "se verificada a desapropriação, cessar a causa que a determinou ou a propriedade não fôr aplicada ao fim para o qual foi desapropriada, considera-se resolvida a desapropriação e o proprietário poderá reivindicá-la".

Ao lado de CLÓVIS, defendendo a impossibilidade da reivindicação e, portanto, a natureza pessoal do direito do expropriado, si-

(2) Direito Administrativo Brasileiro, ed. Rev. Tribs., 1966, pág. 505. Retrocessão é denominação em uso. PONTES DE MIRANDA endereça-lhe crítica, dizendo-a resultado da falsa teoria de cessão forçada (Comentários à Constituição de 1946, ed. Max Limonad, 1963, vol. IV, p. 234). PAULO HENRIQUE BLASI prefere o têrmo "reversão" (Da Desapropriação e da Reversão do Bem Expropriado, Florianópolis, 1967).

(3) Lei n.o 1.102, de 26 de agôsto de 1908.

(4) Exposição de Motivos do Decreto-Lei n. 03.365 , de 21.6.41, item VIII.

( 5) Código Civil Comentado, 7.a ed., 1946, vol IV, pág. 318. 
iUam-se F. WHITAKER ( $\left.{ }^{6}\right)$, EBERT CHAMOUN (7), MUCIO DE CAMPOS MAIA $\left({ }^{8}\right)$ e CAIO MARIO DA SILVEIRA PEREIRA $\left({ }^{9}\right)$, para os quais a não aplicação do bem à finalidade prevista ou o desvio da destinação dariam ao expropriado o direito de prelação. Em se tratando de preempção legal, nem a prerrogativa contida no artigo 313 do Código de Processo Civil poderia ser utilizada, pois que a faculdade de - preferente exigir de terceiro a coisa alienada com inobservância da preferência só teria cabimento na preempção convencional. Em sentido oposto, SOLIDONIO LEITE $\left({ }^{10}\right)$, J. OLIVEIRA E CRUZ $\left({ }^{1}\right)$, EURICO SODRE $\left({ }^{17}\right)$ e AGOSTINHO ALVIM $\left({ }^{13}\right)$, sustentam constituir a retrocessão um direito real.

O Decreto-Lei n. ${ }^{\circ} 3.365$ fornece argumento favorável aos seguidores da primeira orientação, ao dispor, no artigo 35 , sôbre a impossibilidade de os bens expropriados, uma vez incorporados à $\mathrm{Fa}$ zenda Pública, serem objeto de reivindicação; tudo se resolve em perda se danos.

A despeito de tal regra, tem-se admitido a reaquisição, pelo expropriado, do bem a que o poder público não deu a destinação préestabelecida. SEABRA FAGUNDES mostra que o dispositivo nada tem a ver com a retrocessão, pois que tem em vista situações resultantes de anulação do ato administrativo expropriatório por motivos de incompetência, de defeito de forma, etc., ou situações conseqüentes à rescisão de sentença prolatada na ação exproprietória; se o ato é invalidado por por falta de motivo ou desvio de finalidade, a norma torna-se inaplicável por inconstitucional, uma vez que o estatuto básico só admite exceções à garantia do direito de propriedade em casos de necessidade ou utilidade públicas, ou interêsse social. Assim, a dar-se validade ao texto, estar-se-ia permitindo, por via oblíqua, a desapropriação sem os pressupostos necessários. $\left({ }^{14}\right)$

Nestas condições, o fundamento material da retrocessão está na Constituição, que garante solenemente o direito de propriedade. Só a necessidade ou utilidade públicas, bem como o interêsse social, autorizam, por exceção, que o titular dêle seja expropriado mediante

\footnotetext{
(6) A Desapropriação, 3.a ed., 1946, pág. 86.

(7) Da Retrocessão nas Dasapropriaçōes, 1959, pág. 37.

( 8) Ensaio sôbre a Retrecessão, Rev. Dir. Adm., vol. 48, pág. 11.

(9) Instituiçōes de Direito Civil, ed. Forense, 1963, vol. III, pág. 147/148.

(10) Desapropriação por Utilidade Pública, ed. 1921, pág. 66.

(11) Da Desapropriação, pág. 121.

(12) A Desapropriação, ed. 1955, págs. 213/214.

(13) Da Compra e Venda e da Troca, ed. Forense, 1961, pág. 189 e seguintes.

(14) Da Deszpropriaçäo no Direito Brasileiro, pág. 468.
} 
prévio e justa indenização em dinheiro. $\left({ }^{15}\right)$ Do contrário, haverá infração a um dos direitos individuais, pois que a faculdade de desapropriar terá sido utilizada além dos limites traçados pela Constituição.

Decorre daí a impropriedade da assimilação entre a retrocessão e o direito de preferência, podendo a primeira ser exercitada independentemente de preceito legal expresso e, até mesmo, contra $\circ$ comando de lei ordinária que negue condições a sua existência.

Baseado em tais premissas, é ainda SEABRA FAGUNDES quem admite a viabilidade de $\circ$ expropriado reivindicar o bem desapropriado, tendo em vista que se há de ter sempre o domínio do Estado como resolúvel, porquanto sujeito à condição do emprêgo da coisa na finalidade para a qual foi ela expropriada: "o indivíduo perde o domínio, sem dúvida, mas êste se resolve, automàticamente, em seu favor, desde o momento em que se verifica, de modo inequívoco, que a coisa teve destino de direito privado e não público. A constałação da inocorrência de causa essencial para legitimar a tomada do bem, faz restaurar o domínio do ex-proprietário, o qual, indo a juízo, vai reivindicar a volta do mesmo ao seu poder, porque ilegìtimamente apropriado por terceiro. É óbvio que sòmente assim se entendendo, tem sentido a garantia constitucional do art. $141,16 .^{\circ}$ parágrafo. E não se compadece com nenhum critério exegético, a interpretação que, a pretexto de entrosar-se com a sistemática da lei civil, frustra, definitivamente, um direito instituído pela Constituição". (16)

Assim também entende VICENTE RAO, para quem "não ocorre, no exercício do direito, uma nova transmissão da propriedade entre expropriante e expropriado; ocorre, sim, a cessação da eficácia da expropriação, mediante resolução da propriedade do expropriante, em conseqüência do fato de não haver dado ao imóvel seu destino regular. Verificada, pois, a condição resolutiva da não aplicação do imóvel ao fim para o qual foi desapropriado, o direito de propriedade de quem sofreu a desapropriação ressurge e se restabelece em tôda a sua plenitude, com tôdas as conseqüências que de direito forem. $\left({ }^{17}\right)$

Nota-se um retôrno à concepção de CARLOS DE CARVALHO, como assinala HELIO MORAES SIQUEIRA. $\left({ }^{18}\right)$ E, como conseqüência, a aplicação à retrocessão das normas sôbre propriedade resolúvel.

(15) JOSÉ FREDERICO MARQUES, in acórdão do 2.0 Grupo de Câms. Civis TJ. SP., Revista dos Tribunais, vol. 229, pág. 122.

(16) Revisła de Direito Administrativo, vol. 78, pág. 15.

(17) O Direito e a Vida dos Direitos, ed. Max Limonad, 1958, 2.0 vol., pág. 390.

(18) A Retrocassão nas Desapropriações, ed. Revista dos Tribunais, 1964, pág. 46. 
4. Mas parece desnecessário recorrer à lei civil para explicar a retrocessão, que merece tratamento exclusivo de Direito Administrativo. Ao submeter-se o Estado ao princípio da legalidade, justificava-se fôsse-lhe aplicado o ordenamento jurídico que elaborara para seus súditos. Atualmente, com o grau de desenvolvimento alcançado pelo Direito Administrativo, tal solução se torna inaceitável. Compreende-se que, à falta de outro sistema, o Código Civil, sob o primado do Direito Privado, tenha-se adiantado em delimitar alguns princípios do Direito Público, atando-os à idéia do contrato, instituição tìpicamente civilista. Tratando-se porém de formulações teóricas, foram por isso mesmo superadas pela evolução doutrinária do Direito Administrativo $\left({ }^{19}\right)$, que, modernamente, em fenômeno inverso, faz estremecer as bases do Direito Civil, porquanto reflete oposição ao liberalismo econômico.

De outra parte, inocorre adequação perfeita entre o instituto da retrocessão e o da propriedade resolúvel. O artigo 647 dá a noção desta figura, que CLOVIS BEVILA.QUA conceituou como a propriedade que, "no próprio título de sua constituição, encerra o princípio que a tem de extinguir, realizada a condição resolutória ou advindo o têrmo". $\left({ }^{21}\right)$ A natureza jurídica do domínio resolúvel também não constitui matéria incontroversa. Uma corrente sustenta tratar-se de modalidade especial de direito real, enquanto outra acredita ser apenas um caso de aplicação das regras gerais relativas à condição e ao têrmo e dos princípios concernentes à dissolução dos contratos. Conciliando essas tendências, ORLANDO GOMES sugere que melhor será singularizar a propriedade resolúvel, destacando-a como uma das modalidades do domínio, mas sem deixar de reconhecer que a revogação dêste é mera conseqüência da resolução do ato jurídico que o originou, acrescentando ainda que a causa da revogação há de ser estabelecida em cláusula informativa de condição ou têrmo. $\left({ }^{22}\right)$

Portanto, o que configura o domínio resolúvel, de que há exemplos típicos no fideicomisso, na retrovenda, na venda a contento e na doação com reversão, é a sua subordinação a um têrmo ou a uma condição.

Evidentemente não há lugar, no ato expropriatório, para a ad-

(19) RUY CIRNE LIMA - O Código Civil e o Direito Administrativo - Revista de Direito Administrativo, vol. 62, pág. 1.

(20) ORLANDO GOMES - Direito Privado (Novos Aspectos), ed. Freitas Bastos, 1961, págs. 5 e seg.

(21) Ob. cit., ed. 1950, vol. III, pág. 195.

(22) Direitos Reais, ed. Forense, 1969, vol. II, pág. 337 a 345. 
jetivação de um têrmo. Se fôsse a priori fixado um prazo para a detenção do bem tomado ao particular, já não haveria desapropriação, porém ocupação temporária. $\left({ }^{23}\right)$

Quanto à condição, conforme observa SERPA LOPES, é expressão utilizada em diversos sentidos; assim, são comumente denominadas condições as cláusulas apostas pelas partes no contrato, sem que se destinem a afetar a existência do negócio jurídico, mas simplesmente modificar-lhe certos efeitos, ou ainda para significar os requisitos que devem concorrer para a subsistência de um determinado fato, ou, finalmente, o estado e o modo de ser de uma pessoa. Entretanto, quando se cogita de negócio condicional, devese por ela entender uma especial qualificação das declarações de vontade destinada a produzir conseqüências jurídicas. $\left({ }^{24}\right)$ Para tanto, há que se ater à definição legal de condição, contida no artigo 114 do Código Civil: "considera-se condição a cláusula que subordina o efeito de um ato jurídico a um evento futuro e incerto".

Adotada esta posição, verifica-se que a finalidade prevista no ato expropriatório difìcilmente pode caracterizar uma condição implícita, pois que na declaração de ser aplicada a coisa a um fim determinado não se encerra nenhum evento incerto, fortuito, aleatório.

Ainda que se esquematize a questão de modo negativo, quando então teríamos que o domínio do expropriante se resolverá se ao bem não fôr dada a destinação pré-estabelecida, mesmo assim a condição resolutiva ficará longe de seu verdadeiro significado. Neste caso, melhor aproximação se dá com a figura do modo ou encargo.

O modo ou encargo, determinação acessória de ônus aplicável a atos de liberalidade, por isso mesmo torna-se inapropriado para rotular o dever de aplicar a coisa à finalidade prèviamente estipulada, embora se assemelhe com êle e com a condição resolutória, em relação à qual é muitas vêzes equiparado. Além de a desapropriação excluir desde logo qualquer idéia de liberalidade, a destinação da coisa, devendo preencher os requisitos de utilidade ou necessidade públicas ou de interêsse social, constitui o seu fundamento primordial e não um elemento acidental. O negócio jurídico de direito privado se perfecciona independentemente de estipulações

(23) A "ocupação temporária" é conceituada como a utilização transitória, remunerada ou gratuita, que o Poder Público faz, compulsòriamente, de bens particulares, para execução de cbras, serviços ou atividades públicas ou de interêsse coletivo (H. LOPES MEIRELLES, ob cit., p. 516).

(24) Curso de Direito Civil, ed. 1960, vol. 1, pág. 487. 
acessórias, que não participam de sua estrutura geral, ao passo que a desapropriação encontra sua razão de ser nos pressupostos traçados pela Constituição.

A acessoriedade é, por igual, inerente à condição, pelo que idêntica objeção pode ser levantada. De outra parte, como sòmente por necessidade ou utilidade públicas ou interêsses social é lícito ao Estado desapropriar, o próprio Código Civil repele a solução privatista que se contém na aplicação à retrocessão da disciplina da propriedade resolúvel. Dispõe o seu artigo 117: "Não se considera condição a cláusula que não derive exclusivamente da vontade das partes, mas decorra necessàriamente da natureza do direito a que acede".

É que a condição - explica CARVALHO SANTOS - "apenas traduz um elemento voluntário do negócio e depende da combinação e acôrdo das partes, não se podendo confundir com as disposições, conditiones juris, que são elementos componentes do ato e que a lei exige, já para a sua existência, já para a sua eficácia, já para que produza efeitos". $\left({ }^{25}\right)$

O Direito Administrativo desconhece a autonomia da vontade, de resto já limitada mesmo no Direito Privado. $\left({ }^{26}\right)$ CIRNE LIMA aponta como traço característico da atividade de administração o estar vinculada, não a uma vontade livremente determinada, porém a um fim alheio à pessoa e aos interêsses particulares do agente ou órgão que a exercita. "O fim, - e não a vontade, - domina tôdas as formas de administração". $\left({ }^{27}\right)$

Cai, assim, um dos elementos configurativos da condição, já que o fim visado pela desapropriação não fica à fixação arbitrária pela vontade do Estado, mas atém-se aos limites definidos em lei com - objetivo último de satisfazer interêsse público. Identifica-se aí uma conditio juris, que também PONTES DE MIRANDA não admite seja confundida com a condição: "Condições e conditiones juris são referentes a acontecimentos futuros. Mas enquanto as condições, em sentido próprio, são postas pelo manifestante ou pelos manifestantes da vontade, as conditiones juris são-no pela lei. - A condição não se há de confundir com algum elemento do suporte factico que seja pressuposto da existência ou da validade do ato jurídico. As conditiones juris entram na classe dos pressupostos de existência ou de validade do ato jurídico". $\left({ }^{28}\right)$

(25) Cód. Civ. Bras. Interpret., ed. Freitas Bastos, 1950, vol. III, pág. 49.

(26) ORLANDO GOMES, Transformaçöes Gerais do Direito das Obrigaçöes, ed. Rev. Tribs., 1967, págs. 10 e seguintes.

(27) Princípios de Direito Administrativo Brasileiro, ed. Sulina, 1954, p. 22.

(28) Tratado de Dir. Privado, 1955, tomo V, ps. 111 e 113. 
A faculdade de desapropriar tem como pressuposto a necessidade ou utilidade pública, bem assim o interêsse social, que serão atendidos com a aplicação do bem à finalidade declarada. A prédestinação, portanto, não constitui condição, visto que decorre necessàriamente do direito a que acede.

5. Quando o Poder expropriante deixa de dar à coisa o emprêgo que justificou a desapropriação, está na realidade subtraindo ao ato declaratório de utilidade pública o seu fundamento constitucional e possibilitando a sua anulação.

A questão, assim equacionada, dispensa que se procure no Direito Civil o substractum jurídico da retrocessão, principalmente quando já não se considera a desapropriação uma compra e venda forçada e, sim, um ato de soberania para cuja execução não se recebe o consentimento do indivíduo. $\left({ }^{29}\right)$ "A desapropriação, ainda quando se dê a composição amigável segundo o artigo 10, verbo "acôrdo", do Decreto-Lei n.o 3.365, não é negócio jurídico. Tratase de ato de direito público com que se exerce o direito formativo extintivo. Ato jurídico stricto sensu". $\left({ }^{30}\right)$

Ato administrativo, a declaração de utilidade pública há de se compor com os elementos que o estruturam, dentre os quais, para o exame da retrocessão, avultam em importância o motivo e a finalidade.

O motivo ou causa ocasional, segundo OSWALDO ARANHA BANDEIRA DE MELLO, corresponde à consideração do fato em face do direito, que influi sôbre a vontade do agente para decidi-lo a praticar o ato ou sôbre o modo de praticá-lo, isto é, ao seu fundamento. $\left({ }^{3}{ }^{1}\right)$ Ou, como diz JOSÉ CRETELLA JÚNIOR, com apoio em SAYAGUÉS LASO, "motivo é a razão de ser do ato, algo que, no mundo administrativo, impulsione o órgão competente da administração a tomar certa decisão, premissa extraída da realidade, que leve à conclusão, objetivada da atitude tomada. O motivo é o suporte fático da decisão, seu fundamento e apoio. As circunstâncias de fato e de direito que, em cada caso, determinam a edição do ato administrativo constituem o motivo do ato". $\left({ }^{32}\right)$

Nas desapropriações, conforme ILDEFONSO MASCARENHAS DA SILVA, a Constituição dispõe que a necessidade pública e o interêsse social são motivos determinantes do ato expropriatório. ${ }^{(33)}$

(29) GABINO FRAGA, Derecho Administrativo, 1952, pág. 614.

(30) PONTES DE MIRANDA, Comentários à Constituição de 1946, ed. Borsoi, 1963, tomo V, pág. 31.

(31) Princípios Gerais de Direito Administrativo, ed. Forense, 1969, vol. I, pág. 467.

(32) Trałado de Direito Administrativo, ed. Forense, 1966, vol. 1, pág. 206.

(33) Desapropriação por Necessidade e Utilidade Pública, 1947, pág. 211. 
A finalidade, a seu turno, traduz o resultado prático visado pelo ato administrativo, as suas conseqüências materiais, para cuja eleição sempre se exige a presença do interêsse público.

A não aplicação do bem à finalidade fixada no ato declaratório, impulso inicial do procedimento de expropriação, ou a sua utilização em finalidade diversa do interêsse público, podem eventualmente configurar desvio de poder, desde que se faça sentir um interêsse pessoal da autoridade administrativa. Haverá, então, nulidade e a desapropriação será invalidada sob tal fundamento, que não é o da retrocessão, onde se dispensa a pesquisa do elemento intencional de quem promove a expropriação. Bastam a inércia da administração ou a utilização da coisa em destinação alheia ao interêsse público, ainda que tais atitudes não se inspirem em móveis egoísticos do agente.

Todavia, a inobservância da destinação prédeterminada é que denota a insubsistência do motivo em que o ato expropriatório se fundou. Revela a ausência da necessidade e da utilidade pública e do interêsse social. E patenteada a inocorrência do motivo gerador do ato de desapropriação, êste ter-se-á por viciado.

"Quando um ato administrativo se funda em motivos ou pressupostos de fato, - escreveu FRANCISCO CAMPOS - sem a consideração dos quais, da sua existência, da sua procedência, da sua veracidade ou autenticidade, não seria o mesmo praticado, pareceme de boa razão que, uma vez verificada a inexistência dos fatos ou a improcedência dos motivos, deva deixar de subsistir o ato que nêles se fundava". $\left({ }^{39}\right)$

Acolhe-se aí a teoria dos motivos determinantes, construção do Conselho de Estado francês e exposta por GASTON JEZZE: "A idéia geral, no direito privado como no direito público, é que os motivos podem influir sôbre o valor jurídico de uma manifestação unilateral de vontade ou de acôrdo bilateral de vontades, se foram determinantes da vontade de realizar um ato jurídico. Se o motivo determinante não existe de fato ou se é ilícito ou imoral, a manifestação de vontade ou o acôrdo bilateral de vontades são irregulares". $\left({ }^{35}\right)$

Se o poder público nega à coisa a destinação de interêsse público, está em verdade evidenciando a inexistência da utilidade, da necessidade pública ou do interêsse social, advindo daí a invali-

(34) Direiło Administrativo, 1.a ed., pág. 122.

(35) Princípios Generales del Derecho Administrativo, Editorial Depalma, B. Aires, 1949, vol. III, pág. 225. 
dade da desapropriação, já que a inautenticidade dos motivos vicia $\circ$ ato administrativo.

A exigência constitucional de ser explicitado o motivo do ato expropriatório, elimina a discrição do Poder Público. Não se pode afirmar que a desapropriação se inicie com um ato vinculado, se como tal fôr considerado apenas aquêle cuja prática a lei impõe ao administrador, desde que reunidas as condições previstas na regra jurídica. É claro que nenhuma norma obriga a Administração a desapropriar, ao contrário, por exemplo, do que ocorre com a promoção da responsabilidade disciplinar do funcionário faltoso, indisponível, sob pena até de condescendência criminosa.

A distinção entre ato administrativo vinculado e discricionário dá a medida da revisão judicial da atividade administrativa. No primeiro caso, o contrôle jurisdicional se verifica amplamente, pois que os limites da apreciação se confundem com os próprios limites da competência conforme previsão legal. Já na segunda hipótese, a do ato discricionário, se a lei deixa ao critério da autoridade administrativa a prática de determinado ato ou o modo de praticá-lo, veda-se ao juiz o ingresso no exame do mérito do ato, pois que, em o fazendo, estaria quebrando o princípio da separação dos podêres, substituindo o agente competente na gestão dos interêsses administrativos. Sòmente a êstes, nos atos discricionários, cabe decidir da conveniência e da oportunidade da atuação, ou seja, resolver sôbre o mérito do ato administrativo.

Entretanto, repetindo MANOEL RIBEIRO, não existem atos discricionários e vinculados puros: "Os casos de competência vinculada, diz WALINE, são a exceção no Direito Administrativo. Mas se há poucos atos em que a Administração é completamente vinculada por lei, também não há dêles em que sua liberdade seja ilimitada. Assim, ela (a Administração) dispõe, em cada caso, de uma certa margem de apreciação, mas está sempre encerrada, mais ou menos estreitamente, por certas prescrições legais". $\left.{ }^{(36}\right)$

Daí dizer-se que há atos parcialmente vinculados ou parcialmente discricionários, quando de prática obrigatória, mas de conteúdo livre, ou quando facultativos, mas regrados em relação a alguns de seus elementos constitutivos.

Torna-se desta maneira fácil entender que, se por um lado ao administrador é dada a opção entre desapropriar e não desapropriar, não se concebendo o contrôle sôbre a oportunidade e a conveniência de tais atitudes, por outro, escolhendo a primeira alternativa, terá

(36) Direito Administrativo, vol. 1, p. 179. 
de executá-la do modo prescrito em lei. Nesse sentido, o ato de desapropriação é vinculado, porque regrado o exercício do poder expropriatório, dando margem a que, no contrôle de sua legalidade, penetre o Judiciário na aferição da autenticidade dos motivos exigidos constitucionalmente. A indispensabilidade da motivação, prevista taxativamente, confere-lhe essa característica.

Assim, quando o ex-proprietário postular a retrocessão do bem, não estará reivindicando-o, mas pleiteando o reconhecimento da invalidade da desapropriação. A reaquisição será efeito da ineficácia do ato declaratório, bem como dos que the sucederam, por falsidade dos motivos externados. Írrito o ato pelo qual se transferiu a coisa ao Estado, restaura-se o domínio do particular.

A razão está pois com JOSÉ FREDERICO MARQUES ao sentenciar que, não cumprida a finalidade, cessam os efeitos da desapropriação pelo desaparecimento da causa do ato jurídico, pelo que tudo deve retornar ao stału quo ante. O ilustre professor de São Paulo, referindo-se à doutrina estrangeira, cita RAFAEL BIELSA: "não se destinando o bem expropriado ao fim que justificou a expropriação, não existe causa, pelo que cessa a razão legal para manter a propriedade, pois "cessante causa legis, cessat lex"; também GUIDO ZANOBI$\mathrm{NI}$ é de opinião coincidente, ao afirmar que se as expropriạções não foram usadas para o fim a que se destinavam, deve-se tê-las por viciadas e anuláveis; finalmente, PAUL DUEZ e GUY DEBEYRE, para os quais "a desapropriação tão só se funda jurìdicamente, na circunstância de ser o bem expropriado necessário para realizar obra de interêsse público, definida pelo ato declaratório de utilidade pública. Se posteriormente à desapropriação, a Administração não realiza a obra, vem a ficar sem base jurídica em face do expropriado. É lógico, pois, que êle possa reaver seu bem, pois que êste não é mais necessário à satisfação do interêsse público". $\left({ }^{37}\right)$

Tudo se resume, destarte, à aplicação da teoria dos motivos determinantes ao ato administrativo expropriatório. Insubsistentes os motivos, de que é sintoma seguro a não utilização do bem ou o seu uso em finalidade que não seja de interêsse público, a desapropriação se torna inválida e ineficaz. A retrocessão é decorrência, não sendo exercitável por meio de reivindicação, mesmo porque o expropriado não será o titular do domínio; êste só se restabelece com o reconhecimento da ausência de fundamento para a expropriação. 


\section{BIBLIOGRAFIA}

EBERT CHAMOUN - Da Retrocessão nas Desapropriações.

MUCIO DE CAMPOS MAIA - Ensaio sôbre a Retrocessão.

HELIO MORAES SIQUEIRA - A Retrocessão nas Desapropriaçöes.

PAULO HENRIQUE BLASI - Da Desapropriação e da Reversão do Bem Expropriado.

M. SEABRA FAGUNDES - Da Desapropriação no Direito Brasileiro. O Contrôle dos Atos

Administrativos pelo Poder Judiciário. Da Contribuição do Código Civil para ○ Direito Administrativo.

F. WHITAKER - A Desapropriação.

SOLIDONIO LEITE - Desapropriação por Utilidade Pública.

J. OLIVEIRA e CRUZ - Da Desapropriação.

EURICO SODRÉ - A Desapropriação.

ILDEFONSO MASCARENHAS DA SILVA - Desapropriação por Necessidade e Ufilidade

Pública.

FRANCISCO CAMPOS - Direto Administrativo.

RUY CIRNE LIMA - Princípios de Direito Administrativo Brasileiro. O Código Civil e o

Direito Administrativo.

OSWALDO ARANHA BANDEIRA DE MELLO - Princípios Gerais de Direito Administrativo.

JOSÉ CRETELLA JÚNIOR - Trałado de Direito Administrativo.

HELY LOPES MEIRELLES - Direito Administrativo Brasileiro.

MANOEL RIBEIRO - Direito Administrativo.

GABINO FRAGA - Derecho Administrativo.

GASTON JÈZE - Princípios Generales de Derecho Administrativo.

PONTES DE MIRANDA - Comentários à Constituição. Tratado de Direito Privado.

CLÓVIS BEVILAQUA - Código Civil Comentado.

M. M. DE SERPA LOPES - Curso de Direito Civil.

J. M. CARVALHO SANTOS - Código Civil Brasileiro Interpretado.

CAIO MÁRIO DA SILVA PEREIRA - Instituiçõos de Direito Civil.

ORLANDO GOMES - Direitos Reais. Contratos. Introdução ao Direito Civil. Direito Privado

(Novos Aspectos).

AGOSTINHO ALVIM - Da Compra e Venda e da Troca.

VICENTE RAO - O Direito e a Vida dos Direitos. 